\title{
Alternating Hyperthyroidism and Hypothyroidism in Graves' Disease: A Case Report and Literature Review
}

\author{
Alya Hassan Alhajjaj*, Maryam M. Al-Said, Aqeelah H. Alkhatam \\ Internal Medicine Department, Qatif Central Hospital, Qatif, KSA \\ Email: ^alhajjajal@yahoo.com
}

How to cite this paper: Alhajjaj, A.H., Al-Said, M.M. and Alkhatam, A.H. (2020) Alternating Hyperthyroidism and Hypothyroidism in Graves' Disease: A Case Report and Literature Review. Case Reports in Clinical Medicine, 9, 361-367.

https://doi.org/10.4236/crcm.2020.912050

Received: November 5, 2020

Accepted: December 7, 2020

Published: December 10, 2020

Copyright ( 2020 by author(s) and Scientific Research Publishing Inc. This work is licensed under the Creative Commons Attribution International License (CC BY 4.0).

http://creativecommons.org/licenses/by/4.0/

\begin{abstract}
Background: Alternating thyroid function between hypo- and hyperthyroidism is a very rare phenomenon attributed to the switch between the types of thyroid stimulating hormone receptor autoantibodies; thyroid stimulating antibody and thyroid stimulating hormone blocking antibody. Case Presentation: We report an 18 years old male who presented with hyperthyroidism attributed to Graves' disease. He was treated with antithyroid medication. During follow up, his thyroid function was switching between hyper- and hypothyroidism which was difficult to treat with antithyroid medication. His laboratory investigations revealed high thyroid stimulating immunoglobulin and TSH binding inhibitory immunoglobulin. Due to the difficultly of managing him with antithyroid medication, he was offered a definitive management for his Graves' disease. Conclusion: This case demonstrates a rare challenging presentation of Graves' disease. Patients presenting with fluctuation in thyroid function between hyper-and hypothyroidism need a definitive management for Graves' disease.
\end{abstract}

\section{Keywords}

Alternating, Hypothyroidism, Hyperthyroidism, Graves, TSHR, Stimulating, Blocking

\section{Introduction}

The estimated prevalence of autoimmune thyroid diseases (AITD) is around 2\% - 5\% [1]. Among the most well-known AITD are Hashimoto Thyroiditis (HT) and Graves' Disease (GD) which usually present as hypothyroidism and hyperthyroidism respectively [1]. There are several reported cases of conversion from 
hyperthyroidism to hypothyroidism in the same patient and vice versa [2] [3].

Alternating hypo- and hyperthyroidism is a very unique challenging clinical entity that can be presented in GD or HT. This can be explained by the presence of two types of thyroid hormone receptor (TSHR) autoantibodies; thyroid stimulating antibody (TSAb) and TSH blocking antibody (TBAb) [4]. These autoantibodies (Abs) may switch from one type to another causing hyper- or hypothyroidism according to the predominant autoantibodies and this is the most likely cause responsible for alternating hyper- and hypothyroidism in some patients with GD [5].

Herein we present an 18-year-old male with GD who presented with oscillating hyper- and hypothyroidism during his disease course.

\section{Case Report}

Our patient is an eighteen years old male. He was referred to our endocrine clinic on May 28, 2019 as a case of hyperthyroidism for further management. He gave history of palpitation, weight loss $(7 \mathrm{~kg})$, sweating, heat intolerance, loose bowel motion ( 3 - 4 times daily), and hand tremors of few months' duration. There was no history of sleep disturbances, neck swelling, dysphagia, dysphonia, or dyspnea. The patient gave history of increasing eye protrusion bilaterally with no eye pain or redness. He admitted smoking for a short period (less than six months) but quit smoking on March 2019. There was no history of any medical illness, surgical operations, or family history of thyroid disease.

Upon presentation, his physical examination revealed anxious young male. His vital signs reveled a blood pressure of $120 / 80 \mathrm{mmHg}$ and pulse rate of 92 bpm. His neck examination showed symmetrical enlarged goiter $(30 \mathrm{~g})$ with bilateral audible bruits. He had bilateral mild Graves orbitopathy. The rest of his systemic examination was unremarkable except for bilateral hand tremors and exaggerated deep tendon reflexes.

His initial investigations showed normal complete blood count and basic metabolic panel. His thyroid function test (TFT) showed thyroid stimulating hormone (TSH) of $0.005 \mathrm{miU} / \mathrm{L}$ (normal, 0.3 - 4.20), free thyroxin (FT4) of 7.77 $\mathrm{ng} / \mathrm{dl}$ (normal, 0.93 - 1.71). His thyroid Ultrasound (US) showed an enlarged thyroid gland, coarse echotexture with increased vascularity and no nodules. Based on his clinical presentation, TFT, and thyroid US findings, the patient was diagnosed with Graves' disease and he was started on Carbimazole $30 \mathrm{mg}$ BID along with propranolol $20 \mathrm{mg}$ TID.

Six weeks later, he presented with similar complaints and similar TFT results. He admitted that he was noncompliant on his medication. He was advised to use his medication regularly and given an outpatient department (OPD) visit after two months. On September 24, 2019, he presented with decreased concentration, sleepiness, and constipation. His TSH was $66.08 \mathrm{miU} / \mathrm{L}$ and FT4 of $0.087 \mathrm{ng} / \mathrm{dl}$ (Table 1). Despite being on antithyroid medication for less than four months, an iatrogenic hypothyroidism due to antithyroid medication was considered. Car- 
bimazole was stopped, but L-thyroxin (LT4) was not administered. Three weeks later (October 13, 2019), he presented again with hyperthyroid symptoms and his TFT was suggestive of hyperthyroidism (Table 1). He was restarted on lower doses of Carbimazole (40 mg per day) with six weeks OPD visit. On December 4, 2019, he presented again with severe hypothyroid symptoms and his TFT was suggestive of hypothyroidism (Table 1). Once again, his antithyroid medication was stopped. He presented again after 18 days only with hyperthyroidism. The patient's condition continued alternating between hyper- and hypothyroidism till October 2020 (five cycles in seventeen months) (Table 1/Figure 1). TSHR autoantibodies were requested and the results revealed high TSHR autoantibodies: thyroid stimulating immunoglobulin (TSI) of 354\% (normal, <140\%) and TSH binding inhibitory immunoglobulin (TBII) of $91 \%$ (normal, $<\mathrm{OR}=16$ ).

Based on his fluctuating clinical picture, he was diagnosed with oscillating (alternating) hyper- and hypothyroidism. Due to the difficultly of managing him with antithyroid medication, he was offered a definitive management of his GD. On October 18, 2020, our patient underwent total thyroidectomy with uneventful postoperative course and discharged on L-thyroxin therapy. Two weeks after discharge, the patient was seen in the clinic and he was doing well.

Table 1. Trends in thyroid stimulating hormones, free triiodothyronine, free thyroxin levels, and management of Graves' disease.

\begin{tabular}{|c|c|c|c|c|}
\hline Date & $\begin{array}{c}\mathrm{TSH}^{1} \\
\mu \mathrm{IU} / \mathrm{L}\end{array}$ & $\begin{array}{c}\mathrm{FT}^{2} \\
\mathrm{ng} / \mathrm{dL}\end{array}$ & $\begin{array}{c}\mathrm{FT}^{3} \\
\mathrm{ng} / \mathrm{dL}\end{array}$ & Treatment \\
\hline May 28, 2019 & 0.005 & 7.77 & NA & $\begin{array}{l}\text { Carbimazole } 30 \mathrm{mg} \text { BID- } \\
\text { propranolol } 20 \mathrm{mg} \text { TID non-compliant }\end{array}$ \\
\hline July 14, 2019 & 0.005 & 7.77 & NA & Carbimazole $30 \mathrm{mg}$ BID \\
\hline Sep 18, 2019 & 66.06 & 0.087 & NA & Stop Carbimazole \\
\hline Oct 13, 2019 & 0.041 & 7.77 & NA & Carbimazole 20 mg BID \\
\hline $\operatorname{Dec} 4,2019$ & 100 & 0.023 & NA & Stop Carbimazole \\
\hline Dec 22, 2019 & 0.06 & 6.69 & 26.83 & Carbimazole 20 mg BID \\
\hline $\operatorname{Jan} 2,2020$ & 0.03 & 3.27 & 11.12 & Carbimazole 10 mg BID \\
\hline Feb 2, 2020 & 0.01 & 4.07 & NA & Carbimazole $20 \mathrm{mg}$ BID \\
\hline March 3, 2020 & 0.01 & 0.6813 & 2.74 & Stop Carbimazole \\
\hline May 10, 2020 & 0.01 & 5.89 & NA & Carbimazole 10 mg BID \\
\hline June 28, 2020 & 3.15 & 0.019 & 2.81 & Stop Carbimazole \\
\hline July 12, 2020 & 0.03 & 1.55 & 6.52 & Carbimazole 10 mg BID \\
\hline Sep 13,2020 & 0.01 & 3.01 & 15.46 & Carbimazole 20 mg BID \\
\hline Oct 15,2020 & 0.235 & 0.53 & 3.24 & Stop Carbimazole \\
\hline
\end{tabular}

Abbreviations: FT4 = free thyroxine; FT3 = free triiodothyronine, TSH = thyroid-stimulating hormone; NA $=$ Not Available. ${ }^{1}$ Normal range is 0.3 to $4.20 \mu \mathrm{IU} / \mathrm{mL} ;{ }^{2}$ Normal range is 0.93 to $1.71 \mathrm{ng} / \mathrm{dL} ;{ }^{3}$ Normal range is $1.95-4.56 \mathrm{ng} / \mathrm{dL}$ 


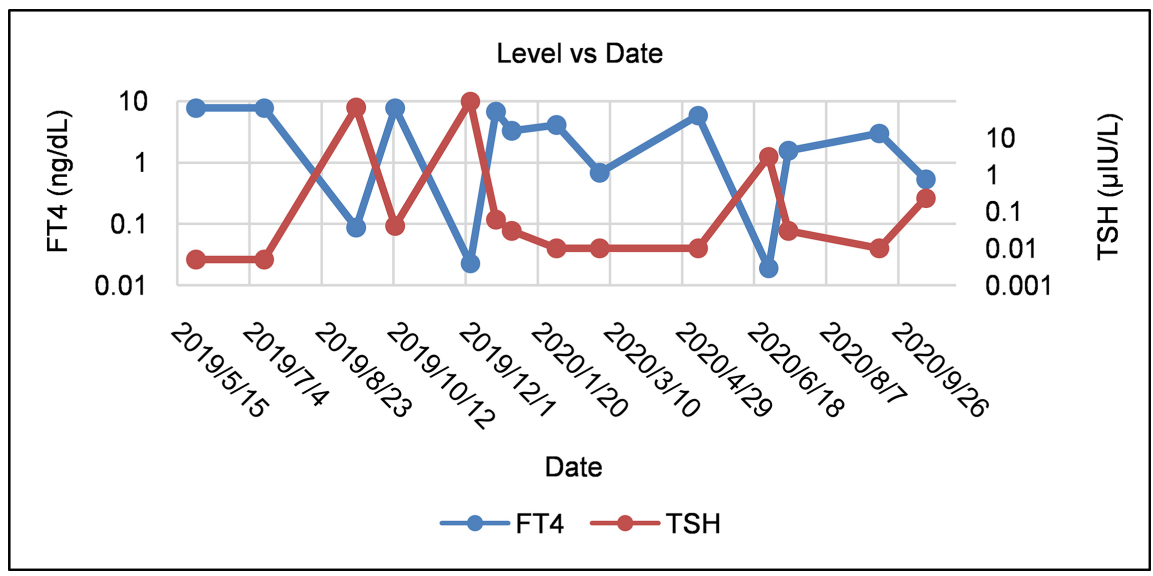

Figure 1. Fluctuating free T4 and TSH values over time. Abbreviations: FT4 = free thyroxine, $\mathrm{TSH}=$ thyroid-stimulating hormone.

\section{Discussion}

Our patient presented with hyperthyroidism due to GD but he developed hypothyroidism following treatment with antithyroid medication. He continued with cycles of alternating hyper- and hypothyroidism reaching five cycles in seventeen months. Few cases of oscillating thyroid function between hyperthyroidism and hypothyroidism had been reported [6] [7] [8]. Although the majority of the reported cases, the duration between hypo- and hyperthyroid phases were long reaching several years, our patient was switching from one phase to another over weeks ranging from 3 - 8 weeks (Table 1 ). This created more challenge in his management.

During the initial phase of his management, our patient developed hypothyroidism with TSH level of $66 \mathrm{miu} / \mathrm{l}$. Though previous studies showed that TSH recovery may take several months during GD management, even with the clinical and biochemical euthyroidism [9], his antithyroid medication was held to test the possibility of iatrogenic hypothyroidism.

Two types of TSHR autoantibodies have been recognized in GD: TSAbs and TBAbs. They are responsible for two different clinical syndromes. TSAbs activate the TSHR causing hyperthyroidism (the most common presentation in GD) [10]. On the other hand, TBAbs inhibit TSH binding competitively to TSHR causing hypothyroidism in GD which is a very rare presentation [11]. Both Abs were high in our patient.

Several mechanisms have been postulated to play a role in changing the level or switching from TBAb to TSAb or vice versa. These may include changes in the immune responses including thyroid Abs levels and intrinsic characteristics of TSHR Abs [12]. Several studies reported that LT4 therapy could change the level of thyroid Abs including thyroid peroxide, thyroglobulin Abs, and TSHR Abs. One study reported that TSHR Abs levels were decreased in hypothyroid patients without goiter after several months of LT4 therapy [13]. On the other hand, other studies have reported increased their levels after L-T4 therapy. For 
example, in one study, $5.9 \%$ of hypothyroid patients developed TSAbs and became hyperthyroid [4]. We can't apply this to our patient since he didn't receive LT4 therapy during his hypothyroid phases.

Laurberg et al reported that treatment with anti-thyroid drugs decrease TSHR Abs and TPO autoantibodies in 70\% - 80\% of GD [14]. Methimazole could prevent the synthesis of autoantibodies in vitro [15]. Furthermore, treatment with antithyroid medication could change the balance between the TSAbs to predominately TBAbs causing hypothyroidism which is similar to the situation of our patient. Recovery of hyperthyroidism itself could reduce the thyroid autoimmunity [16].

These rare unique patients who switch from TBAb to TSAb (or the reverse) may have other characteristics that differentiate them from other patients [2] [17]. These characteristics could be related to ethnicity or sex [12]. The majority of these patients are women. Most reported cases were from Japan, China, United Kingdom, and Israel. To investigate the possibility of genetic predisposition, these patients may need to undergo screening for the whole genome [12].

Due to the difficulty in the management of these patients presenting with alternating hyper- and hypothyroidism, a definitive therapy such as thyroidectomy or radioactive ablation is needed. Our patient underwent total thyroidectomy on October 2020.

\section{Conclusion}

Our patients had Graves' disease with a unique challenging presentation. Clinician should be aware of this rare entity when their patients present with fluctuation in thyroid function. The switching between the types of TSHR autoantibodies is the most likely cause responsible for this phenomenon. These patients need a definitive management of their Graves' disease.

\section{Conflicts of Interest}

All authors declare that there is no conflict of interest.

\section{References}

[1] Simmonds, M.J. and Gough, S.C. (2004) Unravelling the Genetic Complexity of Autoimmune Thyroid Disease: HLA, CTLA-4 and Beyond. Clinical \& Experimental Immunology, 136, 1-10. https://doi.org/10.1111/j.1365-2249.2004.02424.x

[2] Takasu, N., Yamada, T., Sato, A., Nakagawa, M., Komiya, I., Nagasawa, Y. and Asawa, T. (1990) Graves' Disease Following Hypothyroidism Due to Hashimoto's Disease: Studies of Eight Cases. Clinical Endocrinology, 33, 687-98. https://doi.org/10.1111/j.1365-2265.1990.tb03906.x

[3] Furqan, S., Haque, N.U. and Islam, N. (2014) Conversion of Autoimmune Hypothyroidism to Hyperthyroidism. BMC Research Notes, 7, 1-4. https://doi.org/10.1186/1756-0500-7-489

[4] Takasu, N. and Matsushita, M. (2012) Changes of TSH-Stimulation Blocking Antibody (TSBAb) and Thyroid Stimulating Antibody (TSAb) over 10 Years in 34 TSBAb-Positive Patients with Hypothyroidism and in 98 TSAb-Positive Graves' Patients with Hyper- 
thyroidism: Reevaluation of TSBAb and TSAb in TSH-Receptor-Antibody (TRAb)-Positive Patients. Journal of Thyroid Research, 2012, Article ID: 182176. https://doi.org/10.1155/2012/182176

[5] Kasagi, K., Hidaka, A., Endo, K., Miyamoto, S., Takeuchi, R., Misaki, T., Sakahara, H. and Konishi, J. (1993) Fluctuating Thyroid Function Depending on the Balance between Stimulating and Blocking Types of TSH Receptor Antibodies: A Case Report. Thyroid, 3, 315-318. https://doi.org/10.1089/thy.1993.3.315

[6] Martins, L.C., Coutinho, A.R., Jerónimo, M., Caetano, J.S., Cardoso, R., Dinis, I. and Mirante, A. (2016) Autoimmune Alternating Hyper- and Hypo-Thyroidism: A Rare Condition in Pediatrics. Endocrinology, Diabetes \& Metabolism Case Reports, 2016, Article ID: 150131. https://doi.org/10.1530/EDM-15-0131

[7] Solaimanzadeh, I., Hossain, M.R., Shiferaw-Deribe, Z. and Sandhu, H. (2019) Alternating Thyroid Status between Thyrotoxicosis and Hypothyroidism in a Patient with Varying Antithyroid Antibodies. AACE Clinical Case Reports, 5, e112-e118. https://doi.org/10.4158/ACCR-2018-0167

[8] Wong, M. and Inder, W.J. (2018) Alternating Hyperthyroidism and Hypothyroidism in Graves' Disease. Clinical Case Reports, 6, 1684-1688.

https://doi.org/10.1002/ccr3.1700

[9] Ross, D.S., Burch, H.B., Cooper, D.S., Greenlee, M.C., Laurberg, P., Maia, A.L., Rivkees, S.A., Samuels, M., Sosa, J.A., Stan, M.N. and Walter, M.A. (2016) 2016 American Thyroid Association Guidelines for Diagnosis and Management of Hyperthyroidism and Other Causes of Thyrotoxicosis. Thyroid, 26, 1343-1421. https://doi.org/10.1089/thy.2016.0229

[10] Rapoport, B., Chazenbalk, G.D., Jaume, J.C. and McLachlan, S.M. (1998) The Thyrotropin (TSH)-Releasing Hormone Receptor: Interaction with TSH and Autoantibodies. Endocrine Reviews, 19, 673-716. https://doi.org/10.1210/edrv.19.6.0352

[11] Endo, K., Kasagi, K., Konishi, J., Ikekubo, K., Okuno, T., Takeda, Y., Mori, T. and Torizuka, K. (1978) Detection and Properties of TSH-Binding Inhibitor Immunoglobulins in Patients with Graves' Disease and Hashimoto's Thyroiditis. The Journal of Clinical Endocrinology \& Metabolism, 46, 734-739. https://doi.org/10.1210/jcem-46-5-734

[12] McLachlan, S.M. and Rapoport, B. (2013) Thyrotropin-Blocking Autoantibodies and Thyroid-Stimulating Autoantibodies: Potential Mechanisms Involved in the Pendulum Swinging from Hypothyroidism to Hyperthyroidism or Vice Versa. Thyroid, 23, 14-24. https://doi.org/10.1089/thy.2012.0374

[13] Khoo, D.H., Eng, P.H., Ho, S.C. and Fok, A.C. (1999) Differences in the Levels of TSH-Binding Inhibitor Immunoglobulins in Goitrous and Agoitrous Autoimmune Thyroiditis after Twelve Months of L-Thyroxine Therapy. Clinical Endocrinology, 51, 73-79. https://doi.org/10.1046/j.1365-2265.1999.00740.x

[14] Laurberg, P., Wallin, G., Tallstedt, L., Abraham-Nordling, M., Lundell, G. and Tørring, O. (2008) TSH-Receptor Autoimmunity in Graves' Disease after Therapy with Anti-Thyroid Drugs, Surgery, or Radioiodine: A 5-Year Prospective Randomized Study. European Journal of Endocrinology, 158, 69-76. https://doi.org/10.1530/EJE-07-0450

[15] McGregor, A.M., Petersen, M.M., McLachlan, S.M., Rooke, P., Smith, B.R. and Hall, R. (1980) Carbimazole and the Autoimmune Response in Graves' Disease. The New England Journal of Medicine, 303, 302-307. https://doi.org/10.1056/NEJM198008073030603

[16] Laurberg, P. (2006) Remission of Graves' Disease during Anti-Thyroid Drug Ther- 
apy. Time to Reconsider the Mechanism? European Journal of Endocrinology, 155, 783-786. https://doi.org/10.1530/eje.1.02295

[17] Kraiem, Z., Baron, E., Kahana, L., Sadeh, O. and Sheinfeld, M. (1992) Changes in Stimulating and Blocking TSH Receptor Antibodies in a Patient Undergoing Three Cycles of Transition from Hypo to Hyper-Thyroidism and Back to Hypothyroidism. Clinical Endocrinology, 36, 211-214.

https://doi.org/10.1111/j.1365-2265.1992.tb00960.x 